\title{
Association between early mobilization or rehabilitation and intensive care unit acquired weakness: A systematic review and meta-analysis of randomized controlled trials.
}

\section{Minghang Li}

Zhengzhou University People's Hospital,Henan Provincial People's Hospital

\section{Mingyue Ding}

Zhengzhou University People's Hospital

\section{Huanzhang Shao}

Henan Provincial People's Hospital

Bingyu Qin ( $\nabla$ nicolasby@126.com )

Henan Provincial People's Hospital https://orcid.org/0000-0002-6554-0708

\section{Xingwei Wang}

Zhengzhou University People's Hospital

\section{Xiafei Zhao}

Zhengzhou University People's Hospital

\section{Shengyong Ren}

Zhengzhou University People's Hospital

\section{Wenxiao Zhang}

Henan Provincial People's Hospital

\section{Ling Ye}

Henan Provincial People's Hospital

\section{Research}

Keywords: Early mobilization, Early rehabilitation, ICU acquired weakness, Early in-bed cycling, Early goaldirected mobilization, Systematic review

Posted Date: December 11th, 2020

DOl: https://doi.org/10.21203/rs.3.rs-125436/v1

License: (c) (1) This work is licensed under a Creative Commons Attribution 4.0 International License. Read Full License 


\section{Abstract \\ Background}

The prognosis of intensive care unit acquired weakness (ICUAW) is poor and the treatment effect is not ideal. At present, some effective and safe early prevention means are urgently needed to reduce its incidence.This study evaluated the effectiveness and safety of early activities or rehabilitation in the prevention of ICUAW.

\section{Methods}

We searched for articles in five electronic databases, including PubMed, EMBASE, the Cochrane Library, the China National Knowledge Infrastructure (CNKI) and Wanfang Med Online. All publications until June, 2020 were searched. We have selected trials investigating early mobilization or rehabilitation as compared to standard of care in critically ill adults. The extracted data included adverse events, the number of patients with ICUAW, the length of stay in the ICU (ICU-LOS) the length of mechanical ventilation (MV) etc.

\section{Results}

The final results showed that compared with the usual care group, early mobilization or rehabilitation reduced the prevalence of ICUAW (RR, 0.73; [0.61, 0.87]; $\left.{ }^{2}=44 \% ; P=0.0006\right)$, ICU-LOS (MD, - 1.47;[2.83, $\left.0.10] ; I^{2}=56 \% ; P=0.04\right)$, length of $M V\left(M D,-1.96 ;[2.41,1.51] ; I^{2}=0 \% ; P=0.00001\right)$, but the mortality (RR, $\left.0.90 ;[0.62,1.32] ; I^{2}=3 \% ; P=0.60\right)$ at ICU discharge was not associated. The subgroup analysis of ICUAW prevalence and ICU-LOS based on the intervention methods showed that early combined rehabilitation could reduce the prevalence of ICUAW (RR, 0.56; $\left.[0.43,0.74] ; I^{2}=34 \% ; P=0.0001\right)$ and shorten the ICU-LOS $\left(M D,-2.21 ;[3.28,0.97] ; I^{2}=23 \% ; P=0.0003\right)$. EGDM was not associated with a decrease in ICUAW prevalence (RR, 0.85; [0.65, 1.09]; $\left.I^{2}=26 \% ; P=0.20\right)$, but it reduced the ICU-LOS (MD, - 2.27; [3.86, 0.68]; $\left.\right|^{2}$ $=0 \% ; P=0.005)$. Early in-bed cycling was not associated with reduced ICUAW prevalence $(R R, 1.25 ;[0.73$, 2.13]; $I 2=0 \% ; P=0.41)$ and ICU-LOS(MD, 2.27; $[0.27,4.80] ; I 2=0 \% ; P=0.08)$.

\section{Conclusions}

Early mobilization or rehabilitation was associated with a shorter length of MV and ICU-LOS, but not mortality. Of course, not all early activities or forms of rehabilitation are effective. The early combined rehabilitation model is effective for the prevention of ICUAW. However, EGDM and early in-bed cycling were not effective in preventing ICUAW.

\section{Background}


ICU acquired weakness (ICUAW) is a common complication in intensive care units, with an incidence of $25-50 \%[1-3]$. ICU-AW patients are at high risk for complications such as weaning difficulties, sepsis, and multiple organ dysfunction syndrome (MODS), which increase mortality, length of stay in the ICU, and the length of mechanical ventilation[4-8]. These patients are still in a state of functional disability and have a poor ability to live independently several years after discharge from the hospital and thus, they place a great burden on families and society. Currently, there are no clear and effective treatment methods to treat or improve the prognosis of ICU-AW[3, 6, 9, 10].

Some studies have found that physical inactivity may be one of the main risk factors for ICUAW, and subsequently, some studies began to focus on the early prevention of ICUAW $[11,12]$. The role of rehabilitation in the rapid recovery of function in patients after surgery and stroke makes it a possible means of early ICUAW prevention[9, 13, 14]. However, different from other clinical departments, patients in the ICU are in critical condition with poor coordination and are often on various kinds of organ support equipment such as extracorporeal membrane oxygenation (ECMO), mechanical ventilation (MV), continuous renal replacement therapy (CRRT), intra-aortic balloon pumps (IABP), etc., which pose challenges in the timing and mode of rehabilitation interventions.

Although studies have shown that the rehabilitation of critically ill patients reduces their length of hospital stay and mechanical ventilation duration, the preventative role of early rehabilitation in ICUAW is controversial. Nickels et al.'s study found that early in-bed cycling did not improve the ICU-AW prevalence, but Schweickert et al.'s study found that early combined rehabilitation reduced the ICU-AW prevalence[15, 16]. Early goal-directed mobilization (EGDM) was developed as a candidate intervention to prevent ICU$\mathrm{AW}$ and to improve function. The definition of EGDM is a program of physiotherapist-directed active physical exercises intended to maximize physical activity at the highest functional level the patient could achieve. However, the studies of Hodgson et al. showed that its application for the prevention of ICUAW did not seem to achieve satisfactory results[17]. Clearly, the effects of early mobilization or rehabilitation are uncertain, and this may be due to differences in the type of intervention.

We systematically reviewed all RCTS involving the prevalence of ICU-AW in early mobilization or rehabilitation. At the same time, the problems caused by ICUAW, such as prolonged mechanical ventilation time and ICU stay time, an increased fatality rate and poor independent function, were also summarized and analyzed. Although similar studies have been published in the past, they did not delve into the reasons.An in-depth heterogeneity analysis was performed in an attempt to identify a safe, early mobilization or rehabilitation pattern that is beneficial for the prevention of ICU-AW.

\section{Methods}

\section{Registration}

This meta-analysis is fully compliant with the Preferred Reporting Items for Systematic Reviews and Meta-Analyses (PRISMA) guidelines[18], and this systematic review has been prospectively registered in 
the international database of prospectively registered systematic reviews, PROSPERO (number CRD42020202361, https://www.crd.york.ac.uk/prospero/).

\section{Search Strategy}

We searched for articles in five electronic databases, including PubMed, EMBASE, the Cochrane Library, the China National Knowledge Infrastructure (CNKI) and Wanfang Med Online. All publications until June 20,2020 were searched without any restriction of countries or article type.

To identify all relevant studies, a search strategy using combinations of subject headings and free-words was adopted. The complete search used for PubMed was: (("Early Ambulation" [MeSH]) OR (((((Accelerated Ambulation [Title/Abstract]) OR (Ambulation, Accelerated [Title/Abstract])) OR (Ambulation, Early [Title/Abstract])) OR (Early Mobilization [Title/Abstract])) OR (Mobilization, Early [Title/Abstract])) OR (Rehabilitation [Title/Abstract]))) AND (("Polyneuropathies" [MeSH]) OR )(((()((()((()((()((((ICU-acquired weakness [Title/Abstract]) OR (critical illness polyneuropathy [Title/Abstract])) OR (critical illness myopathy [Title/Abstract])) OR (Polyneuropathy [Title/Abstract])) OR (Polyneuropathy, Motor [Title/Abstract])) OR (Motor Polyneuropathies [Title/Abstract])) OR (Motor Polyneuropathy [Title/Abstract])) OR (Polyneuropathies, Motor [Title/Abstract])) OR (Polyneuropathy, Familial [Title/Abstract])) OR (Familial Polyneuropathies [Title/Abstract])) OR (Familial Polyneuropathy [Title/Abstract])) OR (Polyneuropathies, Familial [Title/Abstract])) OR (Polyneuropathy, Inherited [Title/Abstract])) OR (Inherited Polyneuropathies [Title/Abstract])) OR (Inherited Polyneuropathy [Title/Abstract])) OR (Polyneuropathies, Inherited [Title/Abstract])) OR (Polyneuropathy, Acquired [Title/Abstract])) OR (Acquired Polyneuropathies [Title/Abstract])) OR (Acquired Polyneuropathy [Title/Abstract])) OR (Polyneuropathies, Acquired [Title/Abstract])) OR (Polyneuropathy, Critical illness [Title/Abstract])) OR (Critical illness Polyneuropathies [Title/Abstract])) OR (Critical illness Polyneuropathy [Title/Abstract])) OR (Polyneuropathies, Critical illness [Title/Abstract]))).

The search strategies were modified for each database to include database-specific descriptors and field names. Reference lists of the relevant studies were hand-searched to identify additional published studies that met our inclusion criteria. A detailed description of our search strategy is included in Additional file 1.

Two reviewers (Li, Ding) independently screened the titles and abstracts to identify articles for full review. They further evaluated the full text of potentially eligible studies, based on the predetermined eligibility criteria. Any disagreements or questions between the reviewers were resolved by discussion, and, when necessary, adjudication by a third reviewer (Qin) or by contacting the corresponding author of the study.

\section{Study Selection}

Studies were eligible for inclusion if they: 1) enrolled adult (age $\geq 18$ year) critically ill patients with shock in medical, surgical, and cardiac ICUs; 2 ) were randomized controlled trials (RCT); 3 ) used early mobilization or rehabilitation in the intervention group; and 4) reported the primary outcome indicator: the incidence of ICU acquired weakness (Clinical Expert Consensus Documents 2009: A framework for diagnosing and classifying intensive care unit-acquired weakness). Participants who had other 
neuromuscular diseases or underwent rehabilitation after an ICU-AW diagnosis, and animal studies were excluded.

\section{Data Extraction}

Two reviewers (Li, Shao) independently and in duplicate extracted the pertinent data from all studies utilizing a predesigned data extraction form. The extracted data included the study design, baseline data, adverse events, intervention method, the number of patients with ICU-AW, ICU-LOS, the length of MV, MRC sum score and mortality. Where these outcomes were reported as medians (interquartile range [IQR]) or median (range) and in the absence of access to record-level data, we used transformation to means (SDs) as described by Wan et al. and Luo et al[19, 20]. Any disagreements were resolved by discussion, consensus, and, when necessary, consultation with a third reviewer (Qin).

\section{Statistical Analysis}

The methodological quality and risk of bias of each eligible trial were independently assessed using the Cochrane Collaboration tool for assessing the risk of bias (RoB2) in randomized trials by two investigators (Li, Ding).

The risk ratios (RRs) and 95\% Cls of the dichotomous data were calculated by the Mantel-Haenszel method for analysis. The mean differences (MDs) and 95\% Cls of the continuous data were calculated by the inverse-variance method for analysis. Cochran's $Q$ test and ${ }^{2}$ tests were performed to assess the impact of study heterogeneity on the results of the meta-analysis. According to the Cochrane review guidelines, if severe heterogeneity was present at $\mathrm{I}^{2}>50 \%$, the random-effects model was chosen; otherwise, the fixed-effects model was used.

To gain insight into the sources of heterogeneity, we used sensitivity analysis and subgroup analysis. Sensitivity analysis was conducted by deleting each study individually to evaluate the quality and consistency of the results. We separately analyzed three prespecified subgroups of RCTs based on the intervention method: early in-bed cycling, early combined rehabilitation, and EGDM. Publication bias was assessed by Egger' $s$ test (with $p<0.05$ considered significant). All meta-analyses are shown in forest plots.

To control for the known effects of age, gender, APACHE II, and sepsis on the prevalence of ICU-AW, Cochran's $\mathrm{Q}$ test and $\mathrm{I}^{2}$ test were applied to these data. All analyses were performed by using STATA version 16.0 and Review Manager Version 5.3.

\section{Results}

The search yielded a total of 2527 studies prior to the removal of 742 duplicates. After screening the titles and abstracts, another 1642 out of the 
remaining 1785 studies were excluded. Another 143 studies were subsequently excluded following fulltext review. The remaining 9 studies

underwent data extraction and quantitative analysis (Fig. 1).

\section{Characteristics of the Studies Analyzed}

A total of 896 patients were enrolled in 9 RCTs, 4 of which were multicenter RCTs, and 5 studies were blinded. The main intervention methods

were early in-bed cycling $(n=2), \operatorname{EGDM}(n=2)$, and early combined rehabilitation $(n=5)$. The majority of the studies were from the general ICU $(n=7)$, followed by the CCU $(n=1)$, SICU $(n=1)$ (Table 1) [15-17, 21-26]. There were no statistically significant differences in age (RR, 0.99; $95 \% \mathrm{Cl}[0.88,1.11] ; \mathrm{I}^{2}=40 \% ; \mathrm{P}$ $=0.85)$, gender(MD, - 0.18; 95\% Cl [-1.51, 1.16]; $\left.\mathrm{I}^{2}=20 \% ; \mathrm{P}=0.80\right)$, sepsis (RR 1.05; $95 \% \mathrm{Cl}[0.87,1.25] ; \mathrm{I}^{2}$ $=0 \% ; \mathrm{P}=0.63)$ or APACHE II (MD, $0.0795 \% \mathrm{Cl}[-0.55,0.69] ; \mathrm{I}^{2}=0 \% ; \mathrm{P}=0.83$ ) (Additional file 1: Fig. $2-5$ ). 
Table 1

Baseline characteristics of patients in the trials included in the meta-analysis. CCU = Coronary Care Unit, SICU = Surgical ICU, MV = Mechanical Ventilation, EGDM = Early Goal-Directed Mobilisation, APACHE II = Acute Physiology and Chronic Health Evaluation II.

\begin{tabular}{|c|c|c|c|c|c|c|}
\hline Author & Study design & Seting & Population & $\begin{array}{l}\text { Treatment } \\
\text { regimen }\end{array}$ & Region & Year \\
\hline \multirow{2}{*}{$\begin{array}{l}\text { Hodgson et } \\
\text { al [17] }\end{array}$} & \multirow{2}{*}{$\begin{array}{l}\text { A Multi-center } \\
\text { Double-blinded } \\
\text { RCT }\end{array}$} & \multirow[t]{2}{*}{ ICU } & \multirow[t]{2}{*}{ MV $₫ 48 \mathrm{~h}$} & EGDM & Australia & \multirow[t]{2}{*}{2016} \\
\hline & & & & Usual care & $\begin{array}{l}\text { New } \\
\text { Zealand }\end{array}$ & \\
\hline \multirow[t]{2}{*}{$\begin{array}{l}\text { Kho et al } \\
{[21]}\end{array}$} & $\begin{array}{l}\text { A Multi-center } \\
\text { Blinded }\end{array}$ & \multirow[t]{2}{*}{ ICU } & \multirow[t]{2}{*}{$M V \geq 96 \mathrm{~h}$} & $\begin{array}{l}\text { Early in-bed } \\
\text { cycling }\end{array}$ & \multirow[t]{2}{*}{ Canadian } & \multirow[t]{2}{*}{2019} \\
\hline & RCT & & & Usual care & & \\
\hline \multirow[t]{2}{*}{$\begin{array}{l}\text { Nickels et al } \\
\text { [15] }\end{array}$} & RCT & \multirow[t]{2}{*}{ ICU } & \multirow[t]{2}{*}{$\mathrm{MV} \otimes 48 \mathrm{~h}$} & $\begin{array}{l}\text { Early in-bed } \\
\text { cycling }\end{array}$ & \multirow[t]{2}{*}{ Australia } & \multirow[t]{2}{*}{2020} \\
\hline & & & & Usual care & & \\
\hline \multirow{3}{*}{$\begin{array}{l}\text { Patel et al } \\
\text { [22] }\end{array}$} & A Multi-center & \multirow[t]{3}{*}{ ICU } & \multirow[t]{3}{*}{ MV } & Early & \multirow[t]{3}{*}{ America } & \multirow[t]{3}{*}{2014} \\
\hline & \multirow[t]{2}{*}{ RCT } & & & rehabilitation & & \\
\hline & & & & Usual care & & \\
\hline \multirow{3}{*}{$\begin{array}{l}\text { Schaller et } \\
\text { al [23] }\end{array}$} & \multirow{3}{*}{$\begin{array}{l}\text { A Multi-center } \\
\text { Double-blinded } \\
\text { RCT }\end{array}$} & \multirow[t]{2}{*}{ SICU } & \multirow[t]{2}{*}{$24 \leq \mathrm{MV} \otimes 72 \mathrm{~h}$} & EGDM & \multirow{3}{*}{$\begin{array}{l}\text { Austria } \\
\text { Germany } \\
\text { America }\end{array}$} & \multirow[t]{2}{*}{2016} \\
\hline & & & & Usual care & & \\
\hline & & \multirow{3}{*}{ ICU } & \multirow{3}{*}{$24 \leq \mathrm{MV} \otimes 72 \mathrm{~h}$} & & & \multirow{3}{*}{2009} \\
\hline \multirow[t]{2}{*}{$\begin{array}{l}\text { Schweickert } \\
\text { et al [16] }\end{array}$} & \multirow[t]{2}{*}{$\begin{array}{l}\text { Double-blinded } \\
\text { RCT }\end{array}$} & & & $\begin{array}{l}\text { Early } \\
\text { combined } \\
\text { rehabilitation }\end{array}$ & \multirow[t]{2}{*}{ America } & \\
\hline & & & & Usual care & & \\
\hline \multirow{3}{*}{$\begin{array}{l}\text { Song et al } \\
\text { [24] }\end{array}$} & \multirow[t]{3}{*}{ RCT } & $\mathrm{CCU}$ & MV and & Early & China & 2019 \\
\hline & & & Cardiac & rehabilitation & & \\
\hline & & & disease & Usual care & & \\
\hline Yu et al [25] & RCT & ICU & $\begin{array}{l}M V \geq 24 \mathrm{~h} \text { and } \\
\text { Respiratory } \\
\text { failure }\end{array}$ & $\begin{array}{l}\text { Early } \\
\text { combined } \\
\text { rehabilitation }\end{array}$ & China & 2019 \\
\hline & & & & Usual care & & \\
\hline Zhu et al & RCT & ICU & APACHE & EGDM & China & 2018 \\
\hline & & & & Usual care & & \\
\hline
\end{tabular}

The risk of bias assessment of 9 studies showed that 4 studies were low-risk, 5 studies had some possible risks of bias, and there were no high-risk studies. A breakdown of each individual study's risk of 
bias per domain is shown in a risk of bias summary plot (Supplemental Digital Content-Fig. 6-7).

\section{Early mobilization or rehabilitation effect on the prevalence of ICUAW (main outcome)}

Nine RCT analyses showed that early mobilization or rehabilitation was associated with a reduced prevalence of ICU-AW (RR, 0.73; 95\% CI [0.61, 0.87]; $\left.\left.\right|^{2}=44 \% ; \mathrm{P}=0.0006\right)$ (Fig. 2). The heterogeneity could not be significantly reduced by performing a sensitivity analysis by removing each study one by one. $\mathrm{A}$ subsequent subgroup analysis based on intervention modalities revealed: early combined rehabilitation (RR, $\left.0.56 ; 95 \% \mathrm{Cl}[0.43,0.74] ; I^{2}=34 \% ; P=0.0001\right)$ could reduce the prevalence of ICUAW, while early inbed cycling (RR, 1.25; 95\% $\left.\mathrm{Cl}[0.73,2.13] ; \mathrm{I}^{2}=0 \% ; \mathrm{P}=0.41\right)$ and $\operatorname{EGDM}\left(\mathrm{RR}, 0.85 ; 95 \% \mathrm{Cl}[0.65,1.09] ; \mathrm{I}^{2}=\right.$ $26 \% ; P=0.20$ ) could not reduce the prevalence of ICUAW (Fig. 3 ). Tests for subgroup differences $I^{2}=$ $76.3 \%$, and the mode of intervention was the source of heterogeneity. The publication bias had no statistical significance by Egger's test $(P=0.193)$ and the funnel plot was basically symmetrical (Additional file 1: Figs. 10-11, Table 2).

\section{Early mobilization or rehabilitation effect on the length of stay in the ICU (ICU-LOS)}

An analysis of eight RCTS showed that early mobilization or rehabilitation did not reduce the ICU-LOS $\left(\mathrm{MD},-2.22 ; 95 \% \mathrm{Cl}[4.57,0.14] ; \mathrm{I}^{2}=92 \% ; \mathrm{P}=0.07\right)$. Sensitivity analysis found that the study of Song et al. was a source of heterogeneity. After excluding this study, early activity or rehabilitation was associated with a shortening of the ICU-LOS (MD, $-1.47 ; 95 \% \mathrm{Cl}[2.83,0.10] ; \mathrm{I}^{2}=56 \% ; \mathrm{P}=0.04$ ) (Additional file 1: Figs. 12-13). Further subgroup analysis showed that EGDM (MD, - 2.27; $95 \% \mathrm{Cl}[3.86,0.68] ;\left.\right|^{2}=0 \% ; \mathrm{P}=$ $0.005)$ and early combined rehabilitation (MD, $\left.-2.21 ; 95 \% \mathrm{Cl}[3.28,0.97] ; I^{2}=23 \% ; \mathrm{P}=0.0003\right)$ could reduce the ICU-LOS. Early in-bed cycling (MD, 2.27; $\left.95 \% \mathrm{CI}[0.27,4.80] ; \mathrm{I}^{2}=0 \% ; \mathrm{P}=0.08\right)$ did not reduce the ICU-LOS (Fig. 4). Tests for subgroup differences $I^{2}=80.8 \%$, and the mode of intervention was the source of heterogeneity. The publication bias had no statistical significance by Egger's test $(P=0.494)$ (Additional file 10Figs. 15, Table 3).

\section{Early mobilization or rehabilitation effect on the length of mechanical ventilation (MV)}

Analysis of 8 RCTS showed that early mobilization or rehabilitation was associated with the length of MV (MD, $\left.-2.28 ; 95 \% \mathrm{Cl}[3.81,0.75] ; I^{2}=90 \% ; P=0.003\right)$. In the sensitivity analysis, it was found that the study by Song et al. was the source of heterogeneity, and after excluding this study, it was found that early mobilization or rehabilitation could reduce the length of $\mathrm{MV}\left(\mathrm{MD},-1.96 ; 95 \% \mathrm{Cl}[2.41,1.51] ; \mathrm{I}^{2}=0 \%\right.$; 0.00001). The publication bias had no statistical significance by Egger's test $(P=0.191)$ (Additional file 1: Figs. 16-18,Table 4). 


\section{Early mobilization or rehabilitation effect on the other outcomes}

Early mobilization or rehabilitation was not related to mortality in the ICU ( $n=5 ; \mathrm{RR}, 0.90 ; 95 \% \mathrm{Cl}[0.62$, 1.32]; $\left.I^{2}=3 \% ; P=0.60\right)$ but is was related to an increase in the MRC sum score $(n=4 ; M D, 2.88 ; 95 \% \mathrm{Cl}$ $\left.[1.09,4.67] ; I^{2}=36 \% ; P=0.002\right)$ and ICU mobility scale ( $n=3 ; M D, 1.07 ; 95 \% \mathrm{Cl}[0.355,1.79] ; I^{2}=0 \% ; P=$ 0.004) (Additional file 1: Figs. 19-21).

\section{Adverse events}

None of the included studies reported serious adverse events related to the intervention that threatened the life of the patients. Five studies reported detailed adverse events, among which hypotension and fatigue were common, but the criteria were not uniform and further statistical analysis was not possible(Additional file 1: Table 5).

\section{Discussion}

We systematically reviewed and meta-analyzed the effects of early mobilization or rehabilitation on ICUAW prevalence, ICU-LOS, the length of MV and other indicators. The final results showed that, compared with the usual care group, early mobilization or rehabilitation reduced the prevalence of ICUAW, shortened the ICU-LOS (excluding Song et al.'s study), reduced the length of MV (excluding Song et al.'s study), and improved functional status at discharge (MRCsum and ICU mobility scale), but the mortality at ICU discharge was not affected.

Sensitivity analysis found that the study of Song et al. was the main source of heterogeneity. After excluding this study, the relationship between early mobilization or rehabilitation and ICU-LOS of critically ill patients was reversed. Since all of the patients included in Song et al.'s study were from the CCU, they were mainly patients with acute myocardial infarction. These patients had fewer basic diseases, and their physical activity was rarely restricted compared to patients in the general ICU, which may be the main reason for the heterogeneity.

The subgroup analysis of ICUAW prevalence and ICU-LOS based on intervention methods showed that early combined rehabilitation could reduce the prevalence of ICUAW and shorten the ICU-LOS. EGDM was not associated with a decrease in the prevalence of ICUAW, but it did reduce the ICU-LOS. Early in-bed cycle did not reduce the prevalence of ICUAW or shorten the ICU-LOS.

Obviously, the intervention mode is one of the sources of heterogeneity. We think that, compared with early in-bed cycling and EGDM, early combined rehabilitation programs may be more suitable for ICUAW high-risk patients with advanced age, hyperglycemia, sepsis, and long-term mechanical ventilation[3, 5, 27-30]. Early in-bed cycling alone is of limited benefit for critically ill patients. At present, there are few studies on EGDM that used an RCT. Hodgson et al. and Schaller et al. used the ICU Mobility Scale (IMS) and the SICU Optimal Mobility Score (SOMS) to determine the maximum daily activity goals to guide 
rehabilitation therapy, but the results were not satisfactory. We need to find more effective targets or scales to guide early rehabilitation[17, 24].

Although in-depth heterogeneity analysis was conducted in this study, the methods of intervention could not be further subdivided due to the small number of included RCTs and the small number of intervention types. At the same time, according to the study of Stevens et al., ICUAW is divided into critical illness polyneuropathy (CIP), critical illness myopathy (CIM) and critical illness polyneuropathy and myopathy (CINM) subtypes, and the risk factors and the prognosis of the different subtypes are different. Whether this difference will affect early mobilization or rehabilitation still needs additional RCTs for verification[31-34].

\section{Conclusions}

Early mobilization or rehabilitation was associated with a shorter length of MV and ICU-LOS, and improved muscle strength and functional status at discharge, but not with mortality. Of course, not all early activities or forms of rehabilitation are effective. The early combined rehabilitation model is effective for the prevention of ICUAW and can significantly shorten the ICU-LOS. However, EGDM and early in-bed cycling are not effective in preventing ICUAW. Future research should focus on more effective, safe, individualized, multimodal combinations of early mobilization or rehabilitation.

\section{Abbreviations}

ICUAW: intensive care unit acquired weakness;CNKI:China National Knowledge Infrastructure; ICU-LOS:the length of stay in the ICU; MRC:Medical Research Council; MODS:multiple organ dysfunction syndrome ECMO:extracorporeal membrane oxygenation;MV:mechanical ventilation;CRRT:continuous renal replacement therapy; IABP:intra-aortic balloon pumps;PRISMA;Preferred Reporting Items for Systematic Reviews and Meta-Analyses; CCU:Coronary Care Unit;SICU:Surgical ICU; EGDM:Early Goal-Directed Mobilisation;APACHE II:Acute Physiology and Chronic Health Evaluation Il;IMS:ICU Mobility Scale;SOMS:the SICU Optimal Mobility Score; CIP:critical illness polyneuropathy; CIM:critical illness myopathy;CINM:critical illness polyneuropathy and myopathy

\section{Declarations}

\section{Acknowledgements}

Funding from the Department Human Resources and Social Security of Henan Province Foundation is gratefully acknowledged.

\section{Authors' contributions}

Prof. Bingyu Qin, Mr. Minghang Li and Ms. Wenxiao Zhang involved in concept and design. Dr. Huangzhang Shao and Mr. Minghang Li searched for the sources and extracted the data. Mr. Minghang 
Li, Ms. Mingyue Ding performed data check.Dr. Huanzhang Shao, Mr. Xingwei Wang and Mr. Ling Ye involved in statistical analysis. Mr. Xiafei Zhao and Mr. Shengyong Ren involved in drafting of the article. All authors contributed to data interpretation.

\section{Funding}

Supported solely by Department Human Resources and Social Security of Henan Province grant number CYQ20180098.

Prof. Bingyu Qin received funding from Department Human Resources and Social Security of Henan Province, grant no ( CYQ20180098).

\section{Availability of data and materials}

All input parameters of the meta-analysis were based on published literature.

\section{Ethics approval and consent to participate}

Not applicable.

\section{Consent for publication}

Not applicable.

\section{Competing interests}

The authors have disclosed that they do not have any potential conflicts of interest.

\section{Author details}

1. Zhengzhou University People’s Hospital『Henan Provincial People’s Hospital『Zhengzhou, Henan, 450003,China.

2. Department of Critical Care Medicine『Henan Provincial People's Hospital『Zhengzhou Key Laboratory for Critical care medicine囚Zhengzhou University People's Hospital囚Zhengzhou, Henan, 450003,China.

\section{References}

1. Stevens RD, Marshall SA, Cornblath DR, Hoke A, Needham DM, de Jonghe B, Ali NA, Sharshar T: A framework for diagnosing and classifying intensive care unit-acquired weakness. Critical care medicine 2009, 37(10 Suppl):S299-308.

2. Fan E, Cheek F, Chlan L, Gosselink R, Hart N, Herridge MS, Hopkins RO, Hough CL, Kress JP, Latronico $\mathrm{N}$ et al: An official American Thoracic Society Clinical Practice guideline: the diagnosis of intensive care unit-acquired weakness in adults. American journal of respiratory and critical care medicine 2014, 190(12):1437-1446. 
3. Vanhorebeek I, Latronico N, Van den Berghe G: ICU-acquired weakness. Intensive care medicine 2020, 46(4):637-653.

4. Thille AW, Boissier F, Ben Ghezala H, Razazi K, Mekontso-Dessap A, Brun-Buisson C: Risk factors for and prediction by caregivers of extubation failure in ICU patients: a prospective study. Critical care medicine 2015, 43(3):613-620.

5. De Jonghe B, Sharshar T, Lefaucheur JP, Authier FJ, Durand-Zaleski I, Boussarsar M, Cerf C, Renaud $\mathrm{E}$, Mesrati F, Carlet $\mathrm{J}$ et al: Paresis acquired in the intensive care unit: a prospective multicenter study. Jama 2002, 288(22):2859-2867.

6. Iwashyna TJ, Ely EW, Smith DM, Langa KM: Long-term cognitive impairment and functional disability among survivors of severe sepsis. Jama 2010, 304(16):1787-1794.

7. van Wagenberg L, Witteveen E, Wieske L, Horn J: Causes of Mortality in ICU-Acquired Weakness. Journal of intensive care medicine 2020, 35(3):293-296.

8. Herridge MS, Batt J, Santos CD: ICU-acquired weakness, morbidity, and death. American journal of respiratory and critical care medicine 2014, 190(4):360-362.

9. Sidiras G, Patsaki I, Karatzanos E, Dakoutrou M, Kouvarakos A, Mitsiou G, Routsi C, Stranjalis G, Nanas S, Gerovasili V: Long term follow-up of quality of life and functional ability in patients with ICU acquired Weakness - A post hoc analysis. Journal of critical care 2019, 53:223-230.

10. Shepherd SJ, Newman R, Brett SJ, Griffith DM: Pharmacological Therapy for the Prevention and Treatment of Weakness After Critical IIIness: A Systematic Review. Critical care medicine 2016, 44(6):1198-1205.

11. Levine S, Nguyen T, Taylor N, Friscia ME, Budak MT, Rothenberg P, Zhu J, Sachdeva R, Sonnad S, Kaiser LR et al: Rapid disuse atrophy of diaphragm fibers in mechanically ventilated humans. The New England journal of medicine 2008, 358(13):1327-1335.

12. Puthucheary ZA, Rawal J, McPhail M, Connolly B, Ratnayake G, Chan P, Hopkinson NS, Phadke R, Dew T, Sidhu PS et al: Acute skeletal muscle wasting in critical illness. Jama 2013, 310(15):15911600.

13. Cumming TB, Churilov L, Collier J, Donnan G, Ellery F, Dewey H, Langhorne P, Lindley RI, Moodie M, Thrift AG et al: Early mobilization and quality of life after stroke: Findings from AVERT. Neurology 2019, 93(7):e717-e728.

14. Langhorne P, Wu O, Rodgers H, Ashburn A, Bernhardt J: A Very Early Rehabilitation Trial after stroke (AVERT): a Phase III, multicentre, randomised controlled trial. Health technology assessment (Winchester, England) 2017, 21(54):1-120.

15. Nickels MR, Aitken LM, Barnett AG, Walsham J, King S, Gale NE, Bowen AC, Peel BM, Donaldson SL, Mealing STJ et al: Effect of in-bed cycling on acute muscle wasting in critically ill adults: A randomised clinical trial. Journal of critical care 2020, 59:86-93.

16. Schweickert WD, Pohlman MC, Pohlman AS, Nigos C, Pawlik AJ, Esbrook CL, Spears L, Miller M, Franczyk M, Deprizio D et al: Early physical and occupational therapy in mechanically ventilated, 
critically ill patients: a randomised controlled trial. Lancet (London, England) 2009, 373(9678):18741882.

17. Hodgson CL, Bailey M, Bellomo R, Berney S, Buhr H, Denehy L, Gabbe B, Harrold M, Higgins A, Iwashyna TJ et al: A Binational Multicenter Pilot Feasibility Randomized Controlled Trial of Early Goal-Directed Mobilization in the ICU*. Critical care medicine 2016, 44(6):1145-1152.

18. Moher D, Liberati A, Tetzlaff J, Altman DG, Group P: Preferred reporting items for systematic reviews and meta-analyses: the PRISMA statement. PLoS Med 2009, 6(7):e1000097.

19. Luo D, Wan X, Liu J, Tong T: Optimally estimating the sample mean from the sample size, median, mid-range, and/or mid-quartile range. Stat Methods Med Res 2018, 27(6):1785-1805.

20. Wan X, Wang W, Liu J, Tong T: Estimating the sample mean and standard deviation from the sample size, median, range and/or interquartile range. BMC medical research methodology 2014, 14:135.

21. Kho ME, Molloy AJ, Clarke FJ, Reid JC, Herridge MS, Karachi T, Rochwerg B, Fox-Robichaud AE, Seely AJE, Mathur $S$ et al: Multicentre pilot randomised clinical trial of early in-bed cycle ergometry with ventilated patients. BMJ Open Respiratory Research 2019, 6(1).

22. Li囚 Y, Jinxia J: Application of bed-mounted bicycle combined with passive joint movement of the upper extremities in patients with acute respiratory failure undergoing mechanical ventilation. Chin $J$ Mod Nurs 2019(21):2734-2738.

23. Patel BK, PohIman AS, Hall JB, Kress JP: Impact of early mobilization on glycemic control and ICUacquired weakness in critically ill patients who are mechanically ventilated. Chest 2014, 146(3):583589.

24. Schaller SJ, Anstey M, Blobner M, Edrich T, Grabitz SD, Gradwohl-Matis I, Heim M, Houle T, Kurth T, Latronico $\mathrm{N}$ et al: Early, goal-directed mobilisation in the surgical intensive care unit: a randomised controlled trial. Lancet (London, England) 2016, 388(10052):1377-1388.

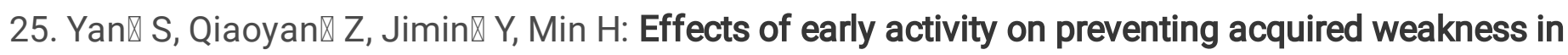
cardiovascular critical surgery patients. Chin J Mod Nurs 2019(36):4786-4789.

26. Zhu Chunyan, Liu Bao, Yang Tianjun, Mei Qing, Pan Aijun, Dongsheng Z: Effect of early rehabilitation physiotherapy on muscle quality and function in critically ill patients. Chin Crit Care Med 2018(06):569-572.

27. Bouju P, Tadié JM, Barbarot N, Letheulle J, Uhel F, Fillatre P, Grillet G, Goepp A, Le Tulzo Y, Gacouin A: Clinical assessment and train-of-four measurements in critically ill patients treated with recommended doses of cisatracurium or atracurium for neuromuscular blockade: a prospective descriptive study. Annals of intensive care 2017, 7(1):10.

28. Cabrera-Serrano M, Fugate JE, Mandrekar J, Rabinstein AA: Impact of Hyperglycemia in the Outcome of Patients with Primary Neuromuscular Respiratory Failure. Neurocritical care 2015, 23(1):103-107.

29. Goossens C, Marques MB, Derde S, Vander Perre S, Dufour T, Thiessen SE, Guiza F, Janssens T, Hermans G, Vanhorebeek I et al: Premorbid obesity, but not nutrition, prevents critical illness-induced muscle wasting and weakness. Journal of cachexia, sarcopenia and muscle 2017, 8(1):89-101. 
30. Wolfe KS, Patel BK, MacKenzie EL, Giovanni SP, Pohlman AS, Churpek MM, Hall JB, Kress JP: Impact of Vasoactive Medications on ICU-Acquired Weakness in Mechanically Ventilated Patients. Chest 2018, 154(4):781-787.

31. Garnacho-Montero J, Madrazo-Osuna J, Garcia-Garmendia JL, Ortiz-Leyba C, Jimenez-Jimenez FJ, Barrero-Almodovar A, Garnacho-Montero MC, Moyano-Del-Estad MR: Critical illness polyneuropathy: risk factors and clinical consequences. A cohort study in septic patients. Intensive care medicine 2001, 27(8):1288-1296.

32. Guarneri B, Bertolini G, Latronico N: Long-term outcome in patients with critical illness myopathy or neuropathy: the Italian multicentre CRIMYNE study. J Neurol Neurosurg Psychiatry 2008, 79(7):838841.

33. Koch S, Spuler S, Deja M, Bierbrauer J, Dimroth A, Behse F, Spies CD, Wernecke KD, Weber-Carstens S: Critical illness myopathy is frequent: accompanying neuropathy protracts ICU discharge. $J$ Neurol Neurosurg Psychiatry 2011, 82(3):287-293.

34. Semmler A, Okulla T, Kaiser M, Seifert B, Heneka MT: Long-term neuromuscular sequelae of critical illness. Journal of neurology 2013, 260(1):151-157.

\section{Figures}




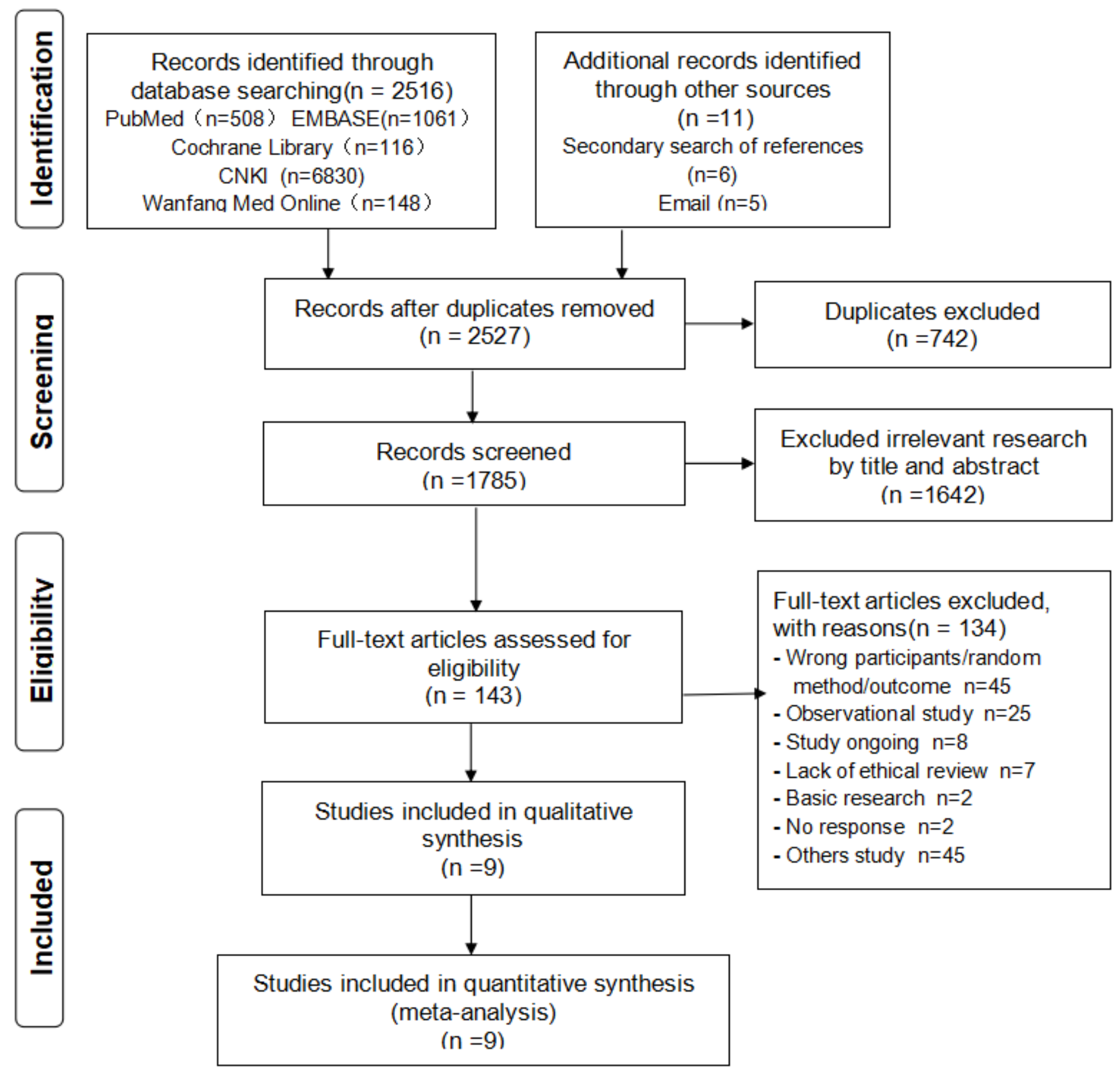

Figure 1

Search and selection process flowchart 


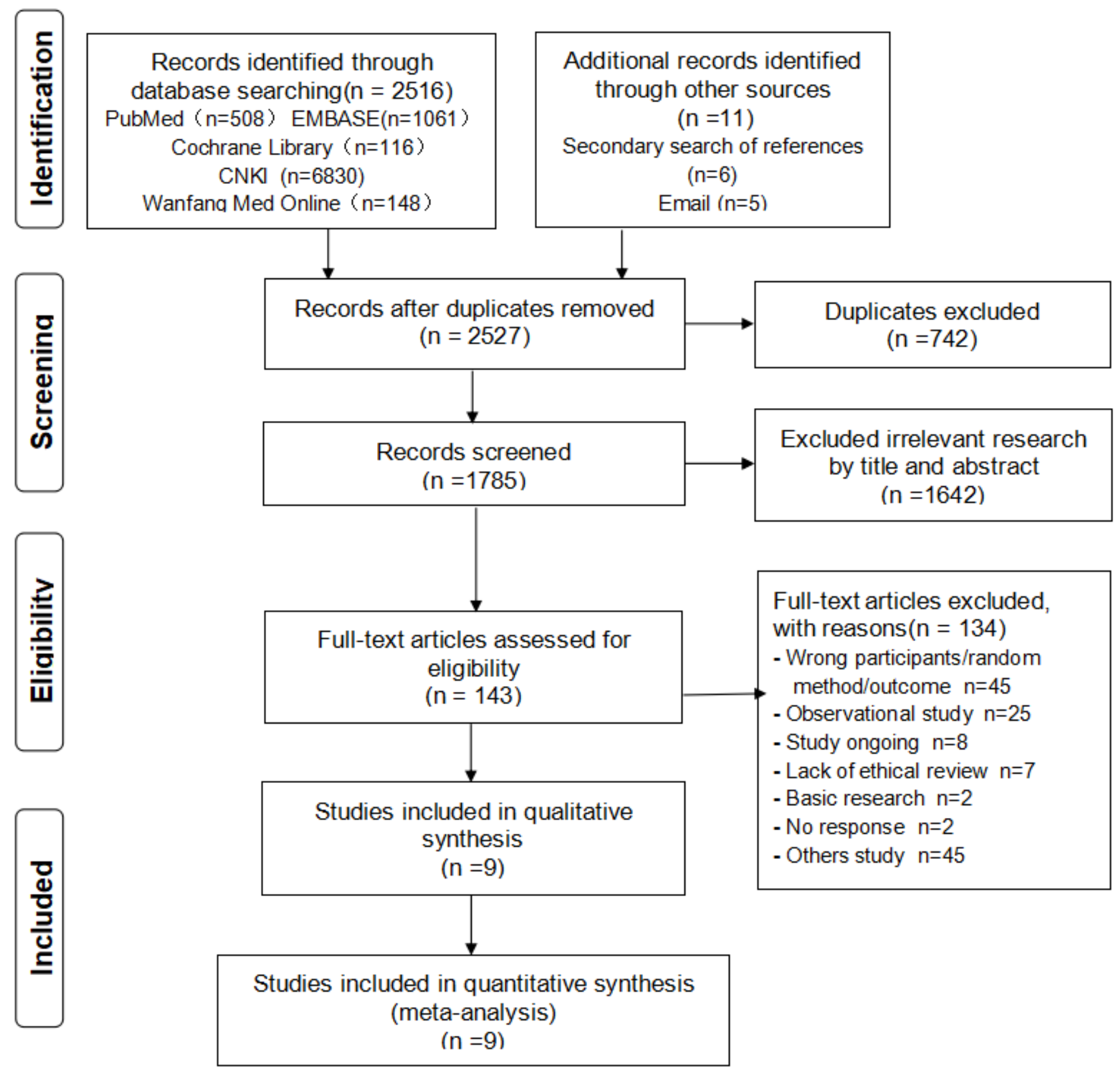

Figure 1

Search and selection process flowchart 


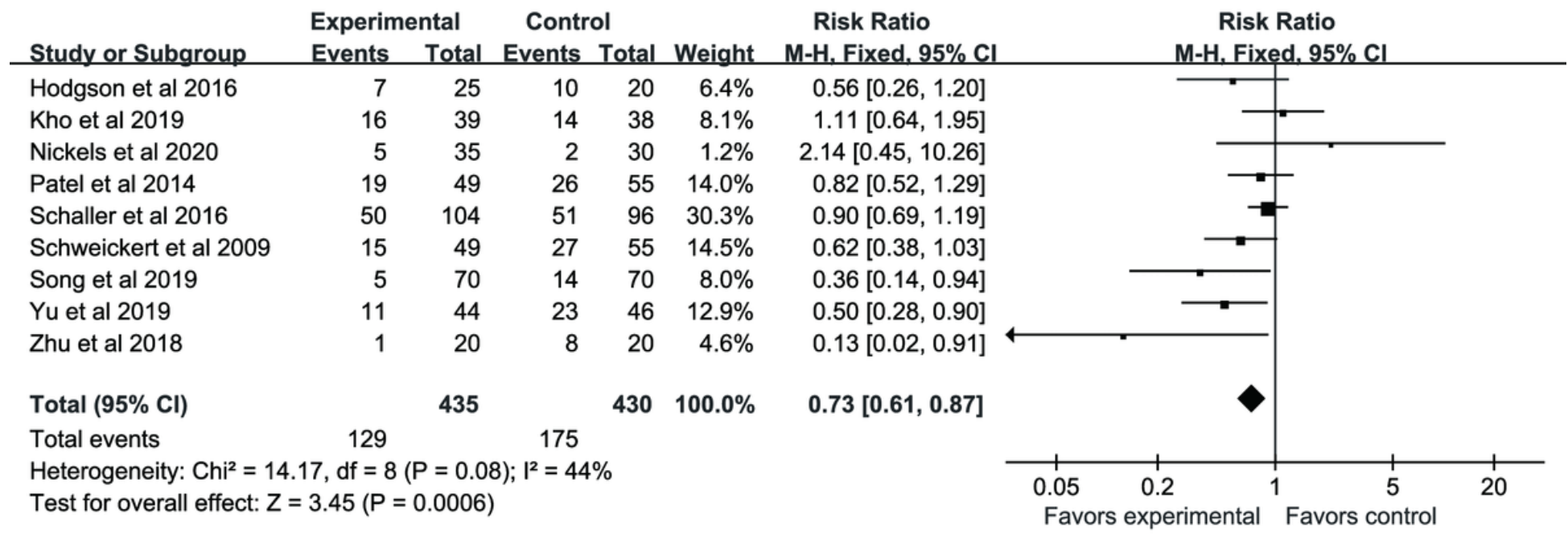

\section{Figure 2}

Forrest plot of the influence of interventions on the prevalence of intensive care unit acquired weakness (ICUAW).

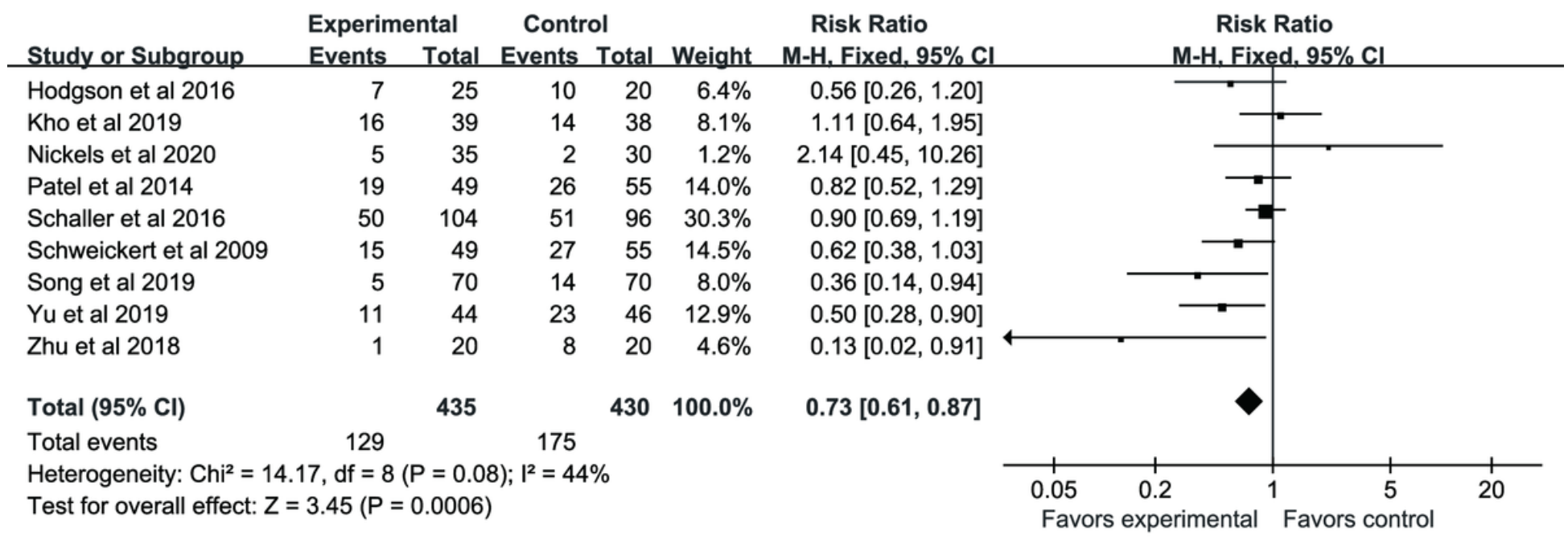

Figure 2

Forrest plot of the influence of interventions on the prevalence of intensive care unit acquired weakness (ICUAW). 


\section{Experimental Control Risk Ratio \\ Risk Ratio}

Study or Subgroup

Events Total Events Total Weight M-H. Fixed, 95\% Cl

1.2.1 Early in-bed cycling

Kho et al 2019

Nickels et al 2020

Subtotal $(95 \% \mathrm{Cl})$

Total events

16

39
35
74

14

$14 \quad 38$

$8.1 \%$

$1.2 \%$

$68 \quad 9.3 \%$

21

16

Heterogeneity: $\mathrm{Chi}^{2}=0.62, \mathrm{df}=1(\mathrm{P}=0.43) ; \mathrm{I}^{2}=0 \%$

Test for overall effect: $Z=0.82(P=0.41)$

\subsubsection{EGDM}

Hodgson et al 2016

Schaller et al 2016

Subtotal $(95 \% \mathrm{Cl})$

$\begin{array}{rr}7 & 25 \\ 50 & 104 \\ & 129\end{array}$

$\begin{array}{rrr}10 & 20 & 6.4 \% \\ 51 & 96 & 30.3 \% \\ & 116 & 36.7 \%\end{array}$

$0.56[0.26,1.20]$

$0.90[0.69,1.19]$

$0.85[0.65,1.09]$

$1.11[0.64,1.95]$

$2.14[0.45,10.26]$

$1.25[0.73,2.13]$

Total events

57 61

Heterogeneity: $\mathrm{Chi}^{2}=1.35, \mathrm{df}=1(\mathrm{P}=0.25) ; \mathrm{I}^{2}=26 \%$

Test for overall effect: $Z=1.28(P=0.20)$

\subsubsection{Early combined rehabilitation}

Patel et al 2014

Schweickert et al 2009

Song et al 2019

Yu et al 2019

Zhu et al 2018

Subtotal $(95 \% \mathrm{Cl})$

Total events

19
15

49

26

$55 \quad 14.0 \%$

$0.82[0.52,1.29]$

$0.62[0.38,1.03]$

$0.36[0.14,0.94]$

$0.50[0.28,0.90]$

$0.13[0.02,0.91]$

$0.56[0.43,0.74]$

M-H. Fixed, $95 \% \mathrm{Cl}$

Heterogeneity: $\mathrm{Chi}^{2}=6.07, \mathrm{df}=4(\mathrm{P}=0.19) ; \mathrm{I}^{2}=34 \%$

Test for overall effect: $Z=4.07(P<0.0001)$

Total $(95 \% \mathrm{Cl})$

Total events

Heterogeneity: $\mathrm{Chi}^{2}=14.17, \mathrm{df}=8(\mathrm{P}=0.08) ; \mathrm{I}^{2}=44 \%$

Test for overall effect: $Z=3.45(P=0.0006)$

Test for subaroun differences: $\mathrm{Chi}^{2}=8.44 . \mathrm{df}=2(\mathrm{P}=0.01) . \mathrm{I}^{2}=76.3 \%$

175

$430 \quad 100.0 \% \quad 0.73[0.61,0.87]$

$$
0.0
$$

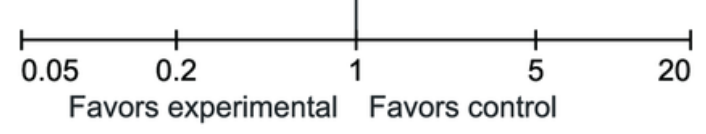

\section{Figure 3}

Forrest plot of subgroup analysis of intensive care unit acquired weakness (ICUAW). 
Experimental Control Risk Ratio

Events Total Events Total Weight $\mathrm{M}-\mathrm{H}$. Fixed. $95 \% \mathrm{Cl}$

Study or Subgroup

1.2.1 Early in-bed cycling

Kho et al 2019

Nickels et al 2020

Subtotal $(95 \% \mathrm{Cl})$

16

$\begin{array}{rr}39 & 14 \\ 35 & 2 \\ 74 & \end{array}$

38

$8.1 \%$

$1.2 \%$

$68 \quad 9.3 \%$

$1.11[0.64,1.95]$

$2.14[0.45,10.26]$

$1.25[0.73,2.13]$

Total events

$21 \quad 16$

Heterogeneity: $\mathrm{Chi}^{2}=0.62, \mathrm{df}=1(\mathrm{P}=0.43) ; \mathrm{I}^{2}=0 \%$

Test for overall effect: $Z=0.82(P=0.41)$

\subsubsection{EGDM}

Hodgson et al 2016

Schaller et al 2016

Subtotal $(95 \% \mathrm{Cl})$

$\begin{array}{rr}7 & 25 \\ 50 & 104 \\ & 129\end{array}$

$\begin{array}{rrr}10 & 20 & 6.4 \% \\ 51 & 96 & 30.3 \% \\ & 116 & 36.7 \%\end{array}$

$0.56[0.26,1.20]$

$0.90[0.69,1.19]$

Total events

$57 \quad 61$

Heterogeneity: $\mathrm{Chi}^{2}=1.35, \mathrm{df}=1(\mathrm{P}=0.25) ; \mathrm{I}^{2}=26 \%$

Test for overall effect: $Z=1.28(P=0.20)$

\subsubsection{Early combined rehabilitation}

Patel et al 2014

Schweickert et al 2009

Song et al 2019

Yu et al 2019

Zhu et al 2018

Subtotal $(95 \% \mathrm{Cl})$

Total events

Heterogeneity: $\mathrm{Chi}^{2}=6.07, \mathrm{df}=4(\mathrm{P}=0.19) ; \mathrm{I}^{2}=34 \%$

Test for overall effect: $Z=4.07(P<0.0001)$

$\begin{array}{rrrrr}19 & 49 & 26 & 55 & 14.0 \% \\ 15 & 49 & 27 & 55 & 14.5 \% \\ 5 & 70 & 14 & 70 & 8.0 \% \\ 11 & 44 & 23 & 46 & 12.9 \% \\ 1 & 20 & 8 & 20 & 4.6 \% \\ & 232 & & 246 & 54.0 \% \\ 51 & & 98 & & \end{array}$

$0.82[0.52,1.29]$

$0.62[0.38,1.03]$

$0.36[0.14,0.94]$

$0.50[0.28,0.90]$

$0.13[0.02,0.91]$

$0.56[0.43,0.74]$

$0.85[0.65,1.09]$

Risk Ratio

M-H. Fixed, $95 \% \mathrm{Cl}$

Total $(95 \% \mathrm{Cl})$

435

$430 \quad 100.0 \%$

Total events 129 175

Heterogeneity: $\mathrm{Chi}^{2}=14.17, \mathrm{df}=8(\mathrm{P}=0.08) ; \mathrm{I}^{2}=44 \%$

Test for overall effect: $Z=3.45(P=0.0006)$

Test for subaroun differences: $\mathrm{Chi}^{2}=8.44 . \mathrm{df}=2(\mathrm{P}=0.01) . \mathrm{I}^{2}=76.3 \%$

$0.73[0.61,0.87]$

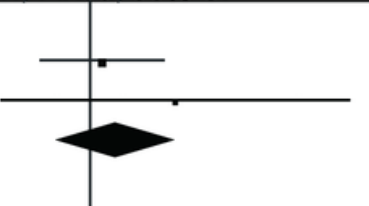

Figure 3

Forrest plot of subgroup analysis of intensive care unit acquired weakness (ICUAW). 


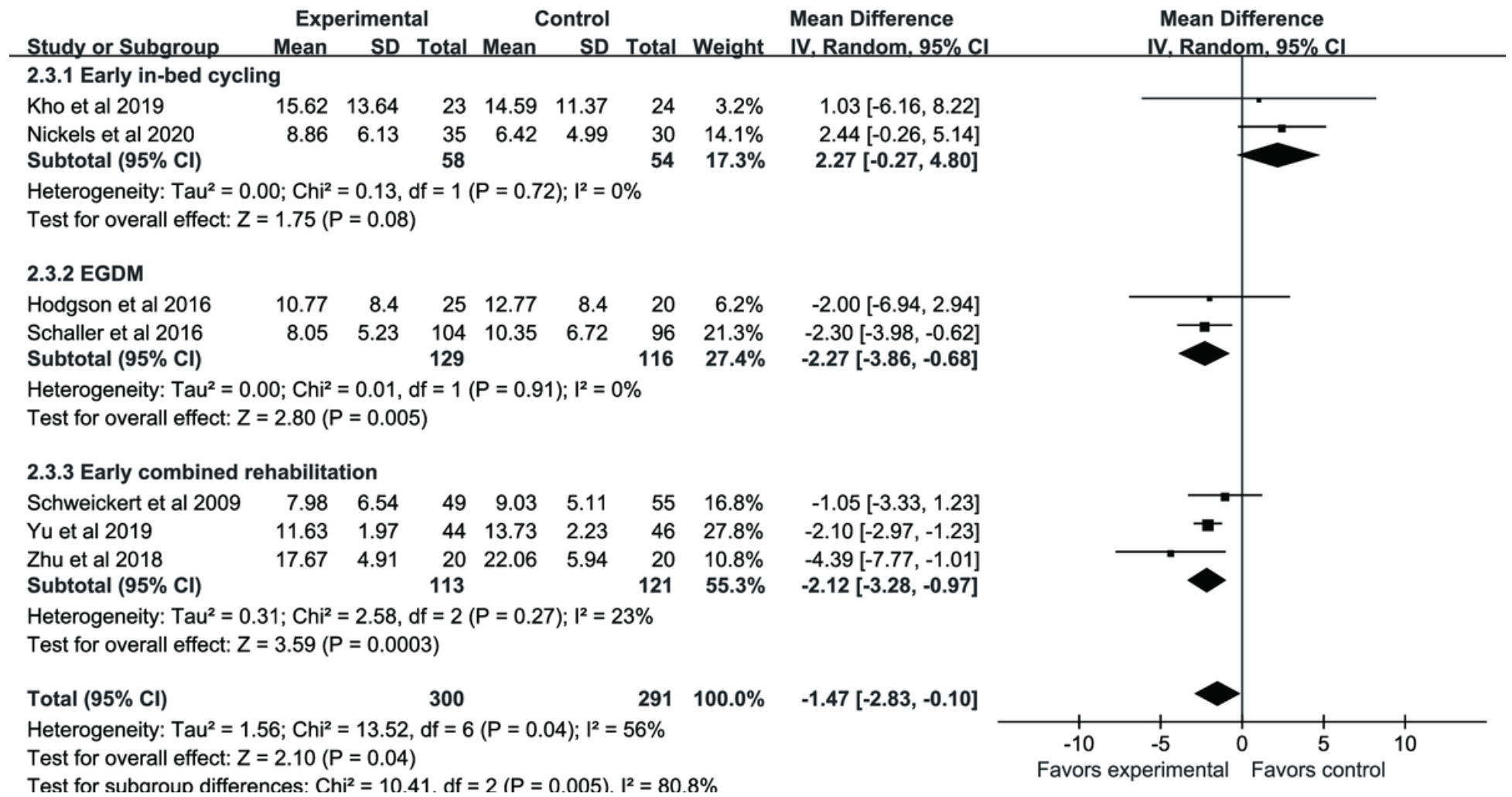

\section{Figure 4}

Forrest plot of subgroup analysis of the length of stay in the ICU (ICU-LOS) (excluding Song et al.'s study).

\begin{tabular}{lrrrrrrrr} 
& \multicolumn{3}{c}{ Experimental } & \multicolumn{2}{c}{ Control } & & Mean Difference \\
Study or Subgroup & Mean & SD & Total & Mean & SD & Total & Weight & IV. Random, 95\% C \\
\hline 2.3.1 Early in-bed cycling & & & & & & & & \\
Kho et al 2019 & 15.62 & 13.64 & 23 & 14.59 & 11.37 & 24 & $3.2 \%$ & $1.03[-6.16,8.22]$ \\
Nickels et al 2020 & 8.86 & 6.13 & 35 & 6.42 & 4.99 & 30 & $14.1 \%$ & $2.44[-0.26,5.14]$ \\
Subtotal (95\% Cl) & & & 58 & & & $\mathbf{5 4}$ & $\mathbf{1 7 . 3 \%}$ & $\mathbf{2 . 2 7}[-0.27, \mathbf{4 . 8 0}]$
\end{tabular}

Heterogeneity: $\mathrm{Tau}^{2}=0.00 ; \mathrm{Chi}^{2}=0.13, \mathrm{df}=1(\mathrm{P}=0.72) ; \mathrm{I}^{2}=0 \%$

Test for overall effect: $Z=1.75(P=0.08)$

\subsubsection{EGDM}

Hodgson et al 2016

Schaller et al 2016

Subtotal $(95 \% \mathrm{Cl})$

$\begin{array}{rrrrr}10.77 & 8.4 & 25 & 12.77 \\ 8.05 & 5.23 & 104 & 10.35 & 6.7 \\ & & 129 & \end{array}$

8.4 $6.72 \quad 96$ 116

Heterogeneity: $\mathrm{Tau}^{2}=0.00 ; \mathrm{Chi}^{2}=0.01, \mathrm{df}=1(\mathrm{P}=0.91) ; \mathrm{I}^{2}=0 \%$

Test for overall effect: $Z=2.80(P=0.005)$

2.3.3 Early combined rehabilitation

$\begin{array}{lrrrrrrrr}\text { Schweickert et al 2009 } & 7.98 & 6.54 & 49 & 9.03 & 5.11 & 55 & 16.8 \% & -1.05[-3.33,1.23] \\ \text { Yu et al 2019 } & 11.63 & 1.97 & 44 & 13.73 & 2.23 & 46 & 27.8 \% & -2.10[-2.97,-1.23] \\ \text { Zhu et al 2018 } & 17.67 & 4.91 & 20 & 22.06 & 5.94 & 20 & 10.8 \% & -4.39[-7.77,-1.01] \\ \text { Subtotal (95\% Cl) } & & & \mathbf{1 1 3} & & & \mathbf{1 2 1} & \mathbf{5 5 . 3 \%} & \mathbf{- 2 . 1 2}[-\mathbf{3 . 2 8}, \mathbf{- 0 . 9 7}]\end{array}$

Heterogeneity: $\mathrm{Tau}^{2}=0.31 ; \mathrm{Chi}^{2}=2.58, \mathrm{df}=2(\mathrm{P}=0.27) ; \mathrm{I}^{2}=23 \%$

Test for overall effect: $Z=3.59(P=0.0003)$

Total $(95 \% \mathrm{Cl})$

Heterogeneity: $\mathrm{Tau}^{2}=1.56 ; \mathrm{Chi}^{2}=13.52, \mathrm{df}=6(\mathrm{P}=0.04) ; \mathrm{I}^{2}=56 \%$

$291 \quad 100.0 \%$

Test for overall effect: $Z=2.10(P=0.04)$

Test for subaroun differences: $\mathrm{Chi}^{2}=10.41 . \mathrm{df}=2(\mathrm{P}=0.005) . \mathrm{I}^{2}=80.8 \%$
$-2.00[-6.94,2.94]$

$-2.30[-3.98,-0.62]$

$-2.27[-3.86,-0.68]$

\section{Figure 4}


Forrest plot of subgroup analysis of the length of stay in the ICU (ICU-LOS) (excluding Song et al.'s study).

\section{Supplementary Files}

This is a list of supplementary files associated with this preprint. Click to download.

- Additionalfile1.pdf

- Additionalfile1.pdf

- Graphicalabstractimage.png

- Graphicalabstractimage.png 